\title{
Betaine in Inflammation: Mechanistic Aspects and Applications
}

\author{
Guangfu Zhao', Fang $\mathrm{He}^{1}$, Chenlu Wu', Pan Li', Nengzhang Li', Jinping Deng ${ }^{2}$, \\ Guoqiang Zhu ${ }^{3}$, Wenkai Ren ${ }^{2,3 *}$ and Yuanyi Peng ${ }^{1 *}$ \\ ${ }^{1}$ College of Animal Science and Technology, Southwest University, Chongqing, China, ${ }^{2}$ Guangdong Provincial Key \\ Laboratory of Animal Nutrition Control, College of Animal Science, Subtropical Institute of Animal Nutrition and Feed, \\ South China Agricultural University, Guangzhou, Guangdong, China, ${ }^{3}$ Jiangsu Co-Innovation Center for Important Animal \\ Infectious Diseases and Zoonoses, Joint International Research Laboratory of Agriculture and Agri-Product Safety of \\ Ministry of Education of China, College of Veterinary Medicine, Yangzhou University, Yangzhou, China
}

OPEN ACCESS

Edited by: Pinyi Lu,

Biotherapeutics, Inc. United States

Reviewed by: Jianlin Geng,

University of Alabama at Birmingham,

United States

Zhenhuan Zhao,

University of Virginia,

United States

Ana María Sanchez-Perez,

Jaume I University,

Spain

*Correspondence: Wenkai Ren

renwenkai19@126.com;

Yuanyi Peng

pyy2002@sina.com

Specialty section: This article was submitted to Nutritional Immunology, a section of the journal

Frontiers in Immunology

Received: 03 March 2018 Accepted: 30 April 2018

Published: 24 May 2018

Citation:

Zhao G, He F, Wu C, Li P, Li N, Deng J, Zhu G, Ren W and Peng $Y$

(2018) Betaine in Inflammation:

Mechanistic Aspects and Applications.

Front. Immunol. 9:1070. doi: 10.3389/fimmu.2018.01070
Betaine is known as trimethylglycine and is widely distributed in animals, plants, and microorganisms. Betaine is known to function physiologically as an important osmoprotectant and methyl group donor. Accumulating evidence has shown that betaine has anti-inflammatory functions in numerous diseases. Mechanistically, betaine ameliorates sulfur amino acid metabolism against oxidative stress, inhibits nuclear factor-кB activity and NLRP3 inflammasome activation, regulates energy metabolism, and mitigates endoplasmic reticulum stress and apoptosis. Consequently, betaine has beneficial actions in several human diseases, such as obesity, diabetes, cancer, and Alzheimer's disease.

Keywords: betaine, oxidative stress, endoplasmic reticulum, inflammation, obesity

\section{INTRODUCTION}

Betaine is a stable and nontoxic natural substance. Because it looks like a glycine with three extra methyl groups, betaine is also called trimethylglycine (1). In addition, betaine has a zwitterionic quaternary ammonium form [(CH3) $3 \mathrm{~N}+\mathrm{CH} 2 \mathrm{COO}-]$ (Figure 1). In the nineteenth century, betaine was first identified in the plant Beta vulgaris. It was then found at high concentrations in several other organisms, including wheat bran, wheat germ, spinach, beets, microorganisms, and aquatic invertebrates (2). Dietary betaine intake plays a decisive role in the betaine content of the body. Betaine is safe at a daily intake of $9-15 \mathrm{~g}$ for human and distributes primarily to the kidneys, liver, and brain (2). The accurate amount of betaine intake generally relies on its various sources and cooking methods (3). Besides dietary intake, betaine can be synthesized from choline in the body. Studies report that high concentrations of betaine in human and animal neonates indicate the effectiveness of this synthetic mechanism $(4,5)$.

Regarding its biological significance, on the one hand, betaine is a vital methyl group donor in transmethylation, a process catalyzed by betaine-homocysteine methyltransferase (BHMT). This reaction catalyzes homocysteine to form methionine and occurs primarily in the liver and kidneys (6). On the other hand, betaine is an essential osmoprotectant, primarily in the kidneys, liver, and brain, and large amounts of betaine can accumulate in cells without disrupting cell function; importantly, this role of betaine protects cells, proteins, and enzymes under osmotic stress (7).

Recently, several studies have focused on various natural compounds proven to be effective against many diseases. For example, Geng and colleagues found that mulberrofuran $G$ has anti-hepatitis B virus activity (8). Interestingly, in Southeast Asia, water extracts of Lycium chinensis, which contains a high concentration of betaine, were used as a traditional oriental medicine to treat liver disorders (9). These findings indicate that the function of betaine, a natural compound, has become a hot topic because of its anti-inflammatory effects on diseases, such as nonalcoholic and alcoholic fatty liver 


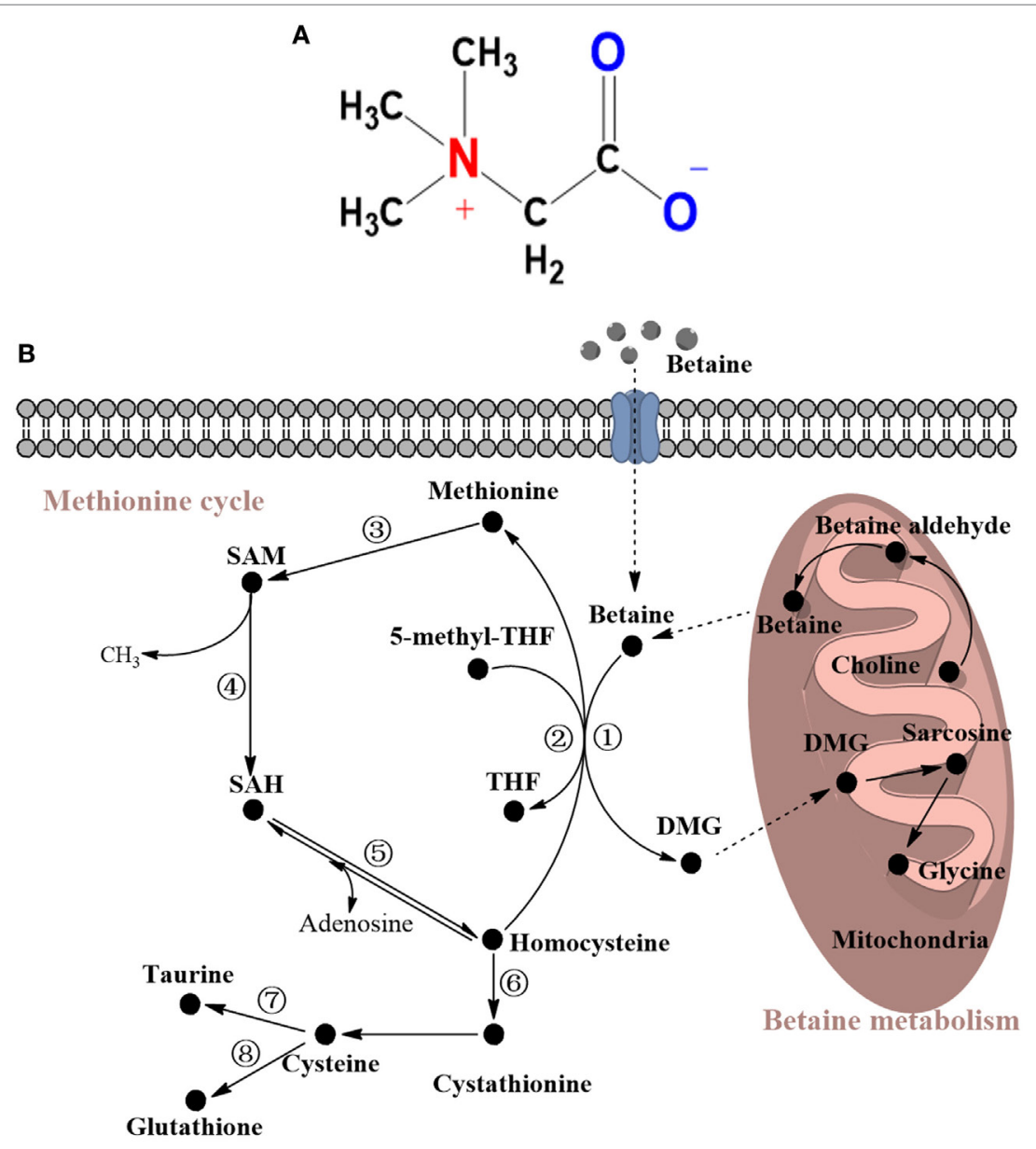

Transsulfuration pathway

FIGURE 1 | (A) Molecular structure of betaine. (B) Metabolism of betaine and related sulfur amino acids (SAAs). Betaine is a substrate of choline and can be converted to DMG via demethylation to ultimately become glycine. Most of these reactions occur in the mitochondria. The demethylation reaction converts homocysteine to methionine and can be replaced by 5 -methyl-THF, which can catalyze methylation to form THF. Then, methionine is successively converted to SAM and finally to homocysteine to form the methionine cycle. Homocysteine can also go through the transsulfuration pathway to form cystathionine, cysteine, taurine, or glutathione. The enzymes mentioned in this review are shown and marked in the cycle with individual numbers. 1. Betaine-homocysteine methyltransferase (BHMT); 2. Methionine synthase (MS); 3. Methionine adenosyltransferase (MAT); 4. SAM-dependent methyltransferases;

5. S-adenosylhomocysteine hydrolase; 6. Cystathionine $\beta$-synthase (CBS); 7. Cysteine dioxygenase (CDO); 8. $\gamma$-glutamylcysteine synthetase (GCS).

THF, tetrahydrofolate; SAM, S-adenosyl-L-methionine; SAH S-adenosyl-L-homocysteine; DMG, N,N-dimethylglycine.

disease (NAFLD and AFLD) and diabetes (10-12). This paper summarizes the role of betaine in physiological functions, antiinflammatory mechanisms, and human diseases.

\section{PHYSIOLOGICAL FUNCTIONS OF BETAINE}

As many studies show, cells from bacteria to vertebrates absorb betaine as an osmoprotectant; animals can rapidly absorb betaine through the duodenum of the small intestine $(13,14)$. Specifically, betaine can be freely filtered in the kidney and reabsorbed into the circulation, so it is primarily excreted in sweat instead of urine $(15,16)$. Betaine accumulation depends on transporters, and it primarily distributes to the kidneys, liver, and brain (2). Although betaine is utilized in most tissues (such as the kidneys and brain) as an osmoprotectant, its primary role is to act as a methyl group donor in liver metabolism $(17,18)$.

\section{Betaine as an Osmoprotectant}

In contrast to inorganic salts, osmoprotectants are highly soluble small organic compounds that accumulate in large amounts in cells without disrupting cell function; these compounds protect against osmotic stress (19). Hyperosmosis can cause water efflux and a concomitant reduction in cell volume; these effects are detrimental to cell survival (20). Thus, to balance hyperosmosis and protect cells from shrinkage and death, the accumulation of different types of osmoprotectants, such as betaine, sorbitol, and taurine, is essential (21-25). In contrast to other osmolytes and inorganic salts, such as urea and $\mathrm{Na}^{+}$, betaine reduces the ability of water molecules to solvate proteins, thus stabilizing the native 
protein structures (26). In addition, betaine can also increase the cytoplasmic volume and free water content of cells to prevent shrinkage in hyperosmotic conditions and to inhibit various hyperosmotic-induced apoptosis-related proteins $(27,28)$. Due to these advantages, additional betaine can be used to counter the pressure when tissues are hypertonic. For example, in the kidneys, hypertonicity increases the levels of the betaine$\gamma$-aminobutyric acid (GABA) transport system (GAT4/BGT1) in the basolateral plasma membrane to obtain more betaine; however, under normal physiological conditions, BGT1 levels are low, and this transporter is present primarily in the cytoplasm in Madin-Darby canine kidney (MDCK) cells (21).

\section{Betaine as a Methyl Group Donor}

Betaine is not only a metabolite of choline but also a methyl group donor that participates in methylation. Methylation, such as that of DNA and protein, is an essential biochemical process in animals. A previous study has shown that the availability of methyl group donors influences methylation levels (29). It has been acknowledged that betaine, methionine, and choline are the most important methyl group donors present in diets. Nevertheless, the major role of methionine is a substrate for protein synthesis, and choline contributes primarily to forming the cell membrane and neurotransmitters. The transmethylation reaction of betaine, which is part of a one-carbon metabolism via the methionine cycle, occurs principally in the mitochondria of liver and kidney cells. In this reaction, BHMT catalyzes the addition of a methyl group from betaine to homocysteine to form methionine, which is subsequently converted to dimethylglycine (DMG) (30). DMG has two available methyl groups and is possibly degraded to sarcosine and ultimately to glycine. Similarly, methionine synthase (MS), a vitamin B12-dependent enzyme, can also catalyze the formation of methionine from homocysteine with a donor methyl group from N5-methyltetrahydrofolate. These reactions are important in animals because they conserve methionine, detoxify homocysteine, which is a cause of cardiovascular disease (31), and produce S-adenosylmethionine (SAM) (32). SAM is generated from methionine via methionine adenosyltransferase (MAT), and SAM is a principal methylating agent. After demethylation, SAM is transformed into S-adenosylhomocysteine (SAH). The ratio of SAM:SAH affects various SAM-dependent methyltransferases, including protein-L-isoaspartate methyltransferase (PIMT), phosphatidylethanolamine methyltransferase (PEMT), protein arginine methyltransferase (PRMT), and isoprenylcysteine carboxyl methyltransferase (ICMT). These enzymes are associated with the protein repair progress, lipid metabolism, protein-protein interactions, and GTPase activity (33-38). One molecule of SAH is subsequently hydrolyzed by $\mathrm{SAH}$ hydrolase to form one homocysteine molecule and one adenosine molecule. Notably, this reaction is reversible, and the direction of the reaction depends on whether these products are removed. All of these reactions constitute the methionine cycle. Furthermore, with the help of cystathionine $\beta$-synthase, a vitamin B-6-dependent enzyme, homocysteine can be transformed into cystathionine via the transsulfuration pathway. In this pathway, homocysteine catabolism leads to an increase in the production of glutathione (GSH), taurine, and other metabolites (39-41).
Dietary betaine supplementation has been demonstrated to have an impact on various sulfur amino acids (SAAs) (2). For example, such supplementation effectively increases the available methionine and SAM $(42,43)$. Therefore, betaine acts as a methyl donor and plays an influential role in SAA metabolism; the details of this metabolic pathway are shown in Figure 1B.

\section{ANTI-INFLAMMATORY EFFECTS OF BETAINE ON DISEASES}

Inflammation, an immune reaction, is an essential and primary process of host defense and wound healing. However, excessive or prolonged inflammation may become the pathogenesis of various diseases. Due to this, using natural compounds to treat diseases could be a good strategy by controlling the intensity of the inflammatory reaction. For instance, many studies show that GABA is anti-inflammatory (44). Consequently, using betaine in response to inflammation has sparked heated debate in recent years. Next, this review will discuss the primary mechanisms through which betaine exerts its anti-inflammatory effects on diseases.

\section{Betaine Ameliorates SAA Metabolism Against Oxidative Stress}

Reactive oxygen species (ROS) are by-products of biological energy-generating reactions; in particular, they are produced in the mitochondria where oxidative metabolism primarily occurs. Under normal conditions, the body has two detoxification systems that can clear ROS and free radicals: antioxidant enzymes and antioxidant agents $(45,46)$. Catalase, superoxide dismutase (SOD), melatonin, and GSH are examples of these detoxification agents (47-49). However, excess ROS levels are a threat to cells because they alter the stability of nucleic acids, proteins, and the lipid membrane; furthermore, high ROS levels likely cause pathological processes, including inflammation (50).

Sulfur amino acids such as homocysteine, methionine, SAM, $\mathrm{SAH}$, and cysteine are involved in various essential metabolic pathways, including GSH synthesis and protein synthesis, and transmethylation reactions. Although homocysteine contributes to GSH synthesis (51), various studies have demonstrated that hyperhomocysteinemia ultimately induces oxidative stress and apoptosis $(52,53)$. Betaine treatment can directly influence homocysteine concentrations via stimulating homocysteine to form methionine to regulate SAA concentrations. For example, ethanol-induced ROS and free radicals can suppress methionine synthase (MS) activity to inhibit remethylation and induce hyperhomocysteinemia (54). To compensate for this decrease in MS activity, betaine was used as an alternate methyl donor that improved BHMT activity to generate methionine and SAM and remove homocysteine in the livers of ethanol-fed Wistar rats $(54,55)$. However, it is worth noting that C57B6 mice showed a decrease or no change in BHMT expression, rather than a compensational increase (56). As betaine converts homocysteine to methionine, methionine concentrations are closely related with betaine. Methionine plays an important role in antioxidation. For example, methionine can reduce oxidative stress via chelation, and it can be used by hepatocytes for GSH synthesis $(57,58)$. 
In addition, this reaction is essential for generating SAM and removing homocysteine. Studies have demonstrated that SAM is a direct antioxidant in the body and that it can modulate GSH metabolism $(59,60)$. Moreover, based on the reversibility of the reaction that converts SAH to homocysteine and adenosine, homocysteine concentrations would further decrease (61). SAH is a powerful inhibitor of SAM-dependent methyltransferases; which methylate various compounds, such as nucleic acids and proteins (62). Kwon and colleagues found that betaine could significantly increase the SAM:SAH ratio and MAT activity (63). Kharbanda and colleagues found that betaine could prevent nitric oxide synthase 2(NOS2) expression; this process is initiated by inflammation, and the SAM:SAH ratio is increased to maintain NOS2 promoter methylation (64). In addition, homocysteine can also be converted to cysteine via the irreversible transsulfuration pathway, and cysteine then forms either taurine via cysteine dioxygenase (CDO) or GSH via $\gamma$-glutamylcysteine synthetase (65). Researchers found that betaine treatment inhibited CDO activity and decreased taurine levels, while increased the production of GSH to neutralize oxidative stress in AFLD and NAFLD mice $(11,63,66)$.

Few studies indicated antioxidant enzymes, such as SOD 2 and glutathione S-transferases (GST), were changed after betaine treatment, but most results have shown no significant changes. Thus, more researches are needed in the future to confirm whether these antioxidant enzymes really participated in the process (55, $67,68)$. Considering the above studies, the primary antioxidant mechanism of betaine may occur through ameliorating SAA metabolism. These changes after betaine treatment and the oxidation-related functions of primary SAAs are shown in Table $\mathbf{1 .}$

\section{Betaine Inhibits the NF-кB Signaling Pathway}

The pathway of the transcription factor nuclear factor- $\kappa \mathrm{B}(\mathrm{NF}-\kappa \mathrm{B})$ controls many genes involved in inflammation; these genes include the pro-inflammatory cytokines tumor necrosis factoralpha (TNF- $\alpha$ ), interleukin 1 beta (IL-1 $\beta$ ) and interleukin 23 (IL-23). Therefore, it is not surprising that many inflammatory diseases involve chronically activation of NF- $\mathrm{KB}(72-74)$. Consequently, the NF- $\mathrm{KB}$ pathway has become an essential candidate for inflammation treatment. Researchers found that betaine can suppress NF- $\mathrm{BB}$ activity and various downstream genes (75-77). For example, in an early study of aged kidneys, betaine treatment suppressed NF- $\kappa \mathrm{B}$ activity and the expression of a variety of related genes, including TNF- $\alpha$, vascular cell adhesion molecule-1 (VCAM-1), intracellular cell adhesion molecule-1
(ICAM-1), inducible nitric oxide synthase (iNOS), and cyclooxygenase-2 (COX-2) (75). Notably, in this and another study about atherogenesis, the authors found that betaine inhibited NF- $\kappa$ B by suppressing two important activators, mitogen-activated protein kinases (MAPKs) and nuclear factor-inducing kinase/ІкB kinase (NIK/IKK) $(75,76)$. NIK/IKK can relieve IאB inhibition and initiate the transcriptional activation of NF- $\kappa B(78)$. MAPKs consist of c-Jun NH2-terminal kinase (JNK), protein 38 (p38), and extracellular signal-regulated kinase (ERK1/2) and are involved in inflammation and the response to pro-inflammatory cytokine expression (79). Mechanistically, betaine exerts its effects by maintaining thiol levels, particularly GSH, to inhibit ROS production and NF- $\kappa$ B activity (80). Furthermore, betaine also inhibits some upstream signaling molecules that induce the activation of NF- $\mathrm{\kappa B}$. Classically, Toll-like receptors (TLRs) participate in an important upstream signaling event, which eventually culminates in activating NF-кB. In an in vitro study, betaine treatment prevented lipopolysaccharide (LPS, specific activator of TLR-4)-induced NF- $\mathrm{KB}$ activation in RAW 264.7 murine macrophage cells (81). Another study showed that betaine treatment improved hypothalamic neural injury via inhibiting the TLR-4/NF- $\kappa$ B signaling pathway to restore fructose-induced astrogliosis and inflammation. This study suggests that betaine can inhibit histone deacetylases 3 expression, which can activate NF- $\kappa \mathrm{B}$ via binding to I $\mathrm{B} \alpha$ (82). Another study showed that betaine treatment can reduce the mRNA and protein expression levels of high-mobility group box 1, a positive regulator of TLR- 4 activation to restrict inflammation (83). In addition, betaine can also reduce endogenous damageassociated molecular pattern (DAMP) generation to inhibit the NF- $\kappa B$ pathway. In conclusion, betaine has anti-inflammatory effects through its inhibition of NF- $\mathrm{KB}$ signaling pathway.

\section{Betaine Inhibits NLRP3 Inflammasome Activation}

The leucine-rich family, pyrin-containing 3 (NLRP3) inflammasome is a large cytosolic protein complex that contains the nucleotide-binding domain, leucine-rich repeat-containing (NLR) family member NLRP3, the important adapter molecule ASC, and mature caspase-1. When TLRs recognize DAMPs or pathogen-associated molecular patterns, NF- $\mathrm{B}$ can be activated to promotes mRNA expression of interleukin precursors, including pro-IL-18 and pro-IL-1 $\beta$, as well as NLRP3 (84). The completely assembled NLRP3 inflammasome activates caspase-1 to mediate the production of mature IL- $1 \beta$ and IL-18, which are involved in initiating inflammation (85). It is important to ameliorate inflammatory reactions via inhibiting NLRP3 inflammasome activity.

TABLE 1 | Changes in the oxidation-related functions of primary sulfur amino acids after betaine treatment.

\begin{tabular}{|c|c|c|c|}
\hline Compound & Change & Functions & Reference \\
\hline Methionine & Upregulated & GSH synthesis; reduces oxidative stress & $(57,58,69)$ \\
\hline S-adenosylmethionine & Upregulated & Increases cellular GSH content; antioxidant & $(59,60)$ \\
\hline S-adenosylhomocysteine & Downregulated & $\begin{array}{l}\text { Inhibits methyltransferases } \\
\text { Induces oxidative stress }\end{array}$ & (62) \\
\hline Homocysteine & Downregulated & Induces oxidative stress; GSH synthesis & $(51-53,70)$ \\
\hline Cysteine & Upregulated & GSH synthesis; reduces oxidative stress & (65) \\
\hline GSH & Upregulated & Antioxidant & $(71)$ \\
\hline
\end{tabular}


Earlier studies have shown that betaine can directly increase heme oxygenase-1 expression levels in hepatocytes (86); this effect may suppress the NLRP3 inflammasome to protect against LPSinduced and D-galactosamine-induced inflammation in the liver $(87,88)$. Recent studies have demonstrated that betaine treatment can significantly inhibit NLRP3 inflammasome-related proteins, such as NLRP3 and mature caspase-1, and the levels of proinflammatory cytokines, including IL- $1 \beta$, in a dose-independent manner in fructose-induced NAFLD models $(82,89,90)$. The same phenomenon was found in betaine-treated $\mathrm{db} / \mathrm{db}$ mice; this finding shows that the mechanism is associated with a forkhead box O1 (FOXO-1) inhibition of thioredoxin-interacting protein (TXNIP), which can promote the production of ROS to trigger NLRP3 inflammasome assembly (12). The FOXO family contains six members, including FOXO-1 and FOXO-6, that are found in mammals. The main role of FOXO factors is the regulation of cell growth, cell death, proliferation, differentiation, and oxidative stress response $(91,92)$. Activated FOXO-1 promotes TXNIP activity, which is the endogenous inhibitor of ROS-scavenging protein thioredoxin, resulting in producing more ROS (93). In addition, activated $\mathrm{PKB} / \mathrm{Akt}$ can phosphorylate the active form of FOXO-1 to trigger its exit from the nucleus into the cytoplasm; this change makes FOXO-1 inactivation (94). In this study, betaine treatment increased the levels of PKB/Aktmediated FOXO-1 phosphorylation. However, Kathirvel and colleagues noted that betaine did not directly activate PKB/Akt, and its mechanism may be the result of enhanced insulin receptor substrate 1 (IRS-1) phosphorylation (10). Thus, we suggest that betaine could enhance IRS- 1 activity to activate PKB/Akt; then, the activated $\mathrm{PKB} /$ Akt would inhibit FOXO-1 activation, which restricts TXNIP to suppress NLRP3 inflammasome components to excise its anti-inflammation effects. Moreover, a study found that betaine mediated inhibition of NLRP3 inflammasome activation played a more important role than that of NF- $\kappa \mathrm{B}$ in response to renal inflammation (90). Overall, the anti-inflammatory effects of betaine are closely associated with its inhibition of NLRP3 inflammasome activation.

\section{Betaine Regulates Energy Metabolism to Relieve Chronic Inflammation}

Energy metabolism disorders can lead to various chronic diseases, including obesity and diabetes, which generally have a systemic low-grade inflammation (95). Thus, restoring normal metabolism is an essential step that contributes to mitigating inflammation. As various reports have reported, betaine has effects on both lipid and glucose metabolism $(10,96)$. Regarding lipid metabolism, excessive fat accumulation resulting from the imbalance of lipid transportation, synthesis, and oxidation is considered to be the culprit of many diseases. Many studies have demonstrated that various factors, such as high-fat diets, antibiotics exposure and ethanol consumption, could lead to such situations $(11,97)$.

Betaine treatment can restore the imbalance between synthesis and oxidation to help attenuate fat accumulation (97-99). Song and colleagues found that an increased hepatic AMP-activated protein kinase (AMPK) activity may be involved mechanistically (98). AMPK serves as both a principal cellular energy sensor and a vital metabolic homeostasis regulator; in fact, AMPK controls many genes, such as sterol regulatory element-binding protein1c (SREBP-1c), acetyl CoA carboxylase (ACC), and fatty acid synthase (FAS). Activated AMPK can inhibit fatty acid synthesis and promote fatty acid oxidation via regulating the expression of these genes (100). Betaine can increase AMPK phosphorylation and then inhibit ACC activity as well as SREBP-1c and FAS expression (98). This result supports the finding of another study in which AMPK could directly phosphorylate SREBP-1c and SREBP-2 at Ser372 to inhibit their activities to reduce lipogenesis and lipid accumulation in diet-induced insulin-resistant mice (101). Furthermore, activated AMPK promotes glucose uptake via improving glucose transporter type 4 (GLUT-4) translocation; these findings suggest a beneficial effect on insulin resistance (102). Regarding the mechanism of AMPK activation, changing the AMP:ATP ratio in cells under normal conditions activates AMPK (103). However, hepatic AMPK activation can occur independently of the AMP:ATP ratio via adiponectin $(104,105)$. Interestingly, in another study from Song, betaine could restore abnormal adipokine levels in NAFLD, and it upregulated adiponectin and downregulated leptin and resistin in adipose cells to attenuate the dysregulated lipid metabolism. Similar effects of betaine are supported by another in vitro study in human adipocytes (106). These results imply that the upregulation of adiponectin may contribute to AMPK phosphorylation (107). In addition, because these adipokines play roles in inflammation, this normalizing process is anti-inflammatory (106). In addition to activating AMPK, betaine treatment could potentially influence other lipid metabolism-related factors. Earlier studies showed that betaine can reduce triglyceride accumulation in apolipoprotein B (apoB)-deficient mice via decreasing peroxisomal proliferator-activated receptor alpha (PPAR $\alpha)$ methylation (108). In another study, betaine restricted PPAR $\gamma$ transcriptional activity via inhibiting FOXO-1 binding to the PPAR $\gamma$ promoter to reduce fat accumulation (109). In a recent study, not only PPAR $\alpha$ but also hepatic liver X receptor $\alpha(\mathrm{LXR} \alpha)$ were upregulated when betaine restored fatty acid oxidation inhibition (89). Although the mechanism of how betaine activates $\operatorname{LXR} \alpha$ remains unclear, it may be associated with a SAM-related enzyme PRMT-3, which can directly increase $\operatorname{LXR} \alpha$ activity (38). In addition, in a study of cisplatin-induced nephrotoxicity, betaine inhibited lipid peroxidation via suppressing renal thiobarbituric acid-reactive substance activation, which is mostly initiated by oxidative stress (110). In addition to altering fat synthesis and oxidation, betaine treatment can ameliorate lipid transport. A study found that betaine maintains liver SAM:SAH ratios to enhance phosphatidylcholine synthesis and normalize very-low-density lipoprotein (VLDL) production via promoting PEMT activity (111), and another study found that betaine stimulates apoB gene expression to form more VLDL (112).

With respect to glucose metabolism, studies have demonstrated that insulin resistance is associated with inflammation $(113,114)$. Morgan and colleagues discovered that betaine supplementation could directly act upon the insulin pathway to improve NAFLD (10). A similar phenomenon has been found in another study of type 2 diabetes (12). In these studies, betaine significantly reduced ser473-phosphorylated $\mathrm{PKB} / \mathrm{Akt}$ levels, but it increased IRS-1 
phosphorylation and thr308-phosphorylated PKB/Akt levels. The $\mathrm{PKB} /$ Akt regulates systemic and cellular metabolism, mainly by mediating cell proliferation, differentiation, and survival, and it is required for insulin signaling $(115,116)$. Then, thr308-phosphorylated $\mathrm{PKB} / \mathrm{Akt}$ could restrict FOXO-1 and glycogen synthase kinase- $3 \alpha$ activities (115). The former can decrease the expression levels of phosphoenolpyruvate carboxy kinase to reduce hepatic gluconeogenesis, whereas the latter can increase glycogen synthesis $(117,118)$. To verify whether betaine can directly initiate PKB/Akt, the authors used a PI3K inhibitor, wortmannin, and found it hard to detect activated $\mathrm{PKB} / \mathrm{Akt}$; these results suggest that betaine may directly enhance IRS-1 phosphorylation rather than directly activate $\mathrm{PKB} / \mathrm{Akt}$ (10). The mechanism of how betaine enhances IRS-1 phosphorylation to improve insulin resistance remains unclear. However, Iwasaki and colleagues recently reported that PRMT-1 can methylate heterogeneous nuclear ribonucleoprotein (hnRNPQ) and may be involved in insulin signaling (119-121). Mechanistically, PRMT-1 can catalyze the addition of a methyl group from SAM to hnRNPQ; this process results in internalization and lasting insulin receptor activation. Notably, SAM concentrations are associated with betaine. Therefore, these evidences speculated that betaine could improve the available SAM to generate more methylation hnRNPQ via PRMT-1 and thus PKB/Akt activation. Besides IRS-PKB/Akt signaling pathway, Chen and colleagues found that betaine treatment could reduce the protein levels of X-box-binding protein-1, an endoplasmic reticulum (ER) stressrelated protein; this reduction is likely to enhance p38-MAPK and mammalian target of rapamycin activities and ultimately reduce hepatic gluconeogenesis and insulin resistance (89). Therefore, we conclude that betaine exerts its anti-inflammatory effects via restoring energy metabolism. These main metabolic pathways and key factors mediated by betaine treatment in chronic inflammation are shown in Table 2.

\section{Betaine Mitigates ER Stress and Apoptosis}

Endoplasmic reticulum (ER) stress is caused by the abnormal assembly of proteins, as either misfolded or unfolded proteins, in the ER lumen (126). Various proteins, such as C/EBP homologous protein (CHOP) and glucose-regulated protein 78 (GRP78), are involved in ER stress, and both of these proteins are ER stress markers (127). Massive ER stress is undesirable and leads to cell apoptosis. Apoptosis is a type of cell death, and takes part in the pathogenesis of inflammatory diseases (128). Although apoptosis has extrinsic and intrinsic pathways, the final process is completed by caspase family proteins, especially caspase-3 (129).

As mentioned, betaine can directly influence the homocysteine pool, and it has been reported that hyperhomocysteine can induce misfolded proteins, ultimately leading to ER stress (70). According to the research by Cheng, betaine can stabilize homocysteine levels and inhibit GRP78 and CHOP levels as well as cell death (130). Likewise, in another study, betaine inhibited both GRP78 and CHOP and reduced JNK activation (107). Interestingly, the JNK pathway can directly phosphorylate multiple IRS-1 sites, including serine-307. These modifications prevent insulin-stimulating IRS-1 tyrosine phosphorylation, which leads to insulin resistance (10). In addition to ER stress, betaine also inhibits apoptosis. In a recent study of rheumatoid arthritis synovial fibroblasts, Gaur and colleagues found that transcription factor-3 (ATF-3), an apoptosis-related molecule, is downregulated by betaine (131). In addition, betaine can inhibit caspase family proteins. In an in vitro study, adding adenosine to hepatocytes increased hepatic SAH levels and caspase- 3 activity, both of which would be inhibited by betaine treatment (132). The inhibition of caspase- 3 by betaine is also found in cisplatin-induced nephrotoxicity (110). Furthermore, betaine significantly reduced caspase- 8 , caspase- 9 , and caspase-3/7 activity in human corneal epithelial cells and MDCK cells under hyperosmotic stress $(28,133)$. Thus, we would like to believe that the mitigation of ER stress and apoptosis by betaine is essential to its anti-inflammatory effects.

\section{APPLICATIONS OF BETAINE IN HUMAN DISEASES}

Recently, the effects of natural and nontoxic substances on human diseases have attracted considerable attention. Researches

TABLE 2 | Main metabolic pathways and genes/proteins influenced by betaine treatment in inflammation diseases.

\begin{tabular}{|c|c|c|c|c|}
\hline Results & Main metabolic pathway & Gene/protein & Function of gene/protein & Reference \\
\hline \multirow[t]{8}{*}{ Lipid metabolism $\uparrow$} & AMPK pathway & $\mathrm{ACC} \uparrow$ & Fatty acid synthesis & \\
\hline & & $\mathrm{FAS} \uparrow$ & Fatty acid synthesis & $(98,100,101)$ \\
\hline & & SREBP-1c $\uparrow$ & Fatty acid synthesis & \\
\hline & Others & PPAR $\alpha \uparrow$ & Fatty acid oxidation & $(108,109)$ \\
\hline & & $\mathrm{PPAR} \gamma \uparrow$ & Fatty acid oxidation & \\
\hline & & $L X R \alpha \uparrow$ & Fatty acid oxidation & (89) \\
\hline & & TBARS $\downarrow$ & Lipid peroxidation & (110) \\
\hline & & Apo $B \uparrow$ & Cholesterol transport & $(111,122)$ \\
\hline \multirow[t]{5}{*}{ Glucose metabolism $\uparrow$} & IRS-1/Akt pathway $\uparrow$ & $\mathrm{IRS}-1 \uparrow$ & Insulin sensitivity & $(10,12,123,124)$ \\
\hline & & 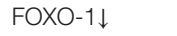 & Gluconeogenesis & \\
\hline & & GSK3 $\alpha \downarrow$ & Inhibits glycogen synthesis & \\
\hline & Others & $\mathrm{XBP}-1 \downarrow$ & Gluconeogenesis & $(89,125)$ \\
\hline & & 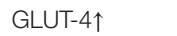 & Glucose transport & (102) \\
\hline
\end{tabular}

The upward arrows indicate promotion.

The downward arrows indicate inhibition. 
have shown that betaine has beneficial effects in various human diseases, such as obesity, diabetes, cancer, and Alzheimer's disease (134-141). Obesity results from excessive fat accumulation and has potentially negative effects on health. Obesity can lead to various secondary diseases, such as NAFLD. In animal studies, dietary betaine has been demonstrated to positively affect body fat $(142,143)$. However, few studies have focused on the effect of betaine on human obesity, and some of the results

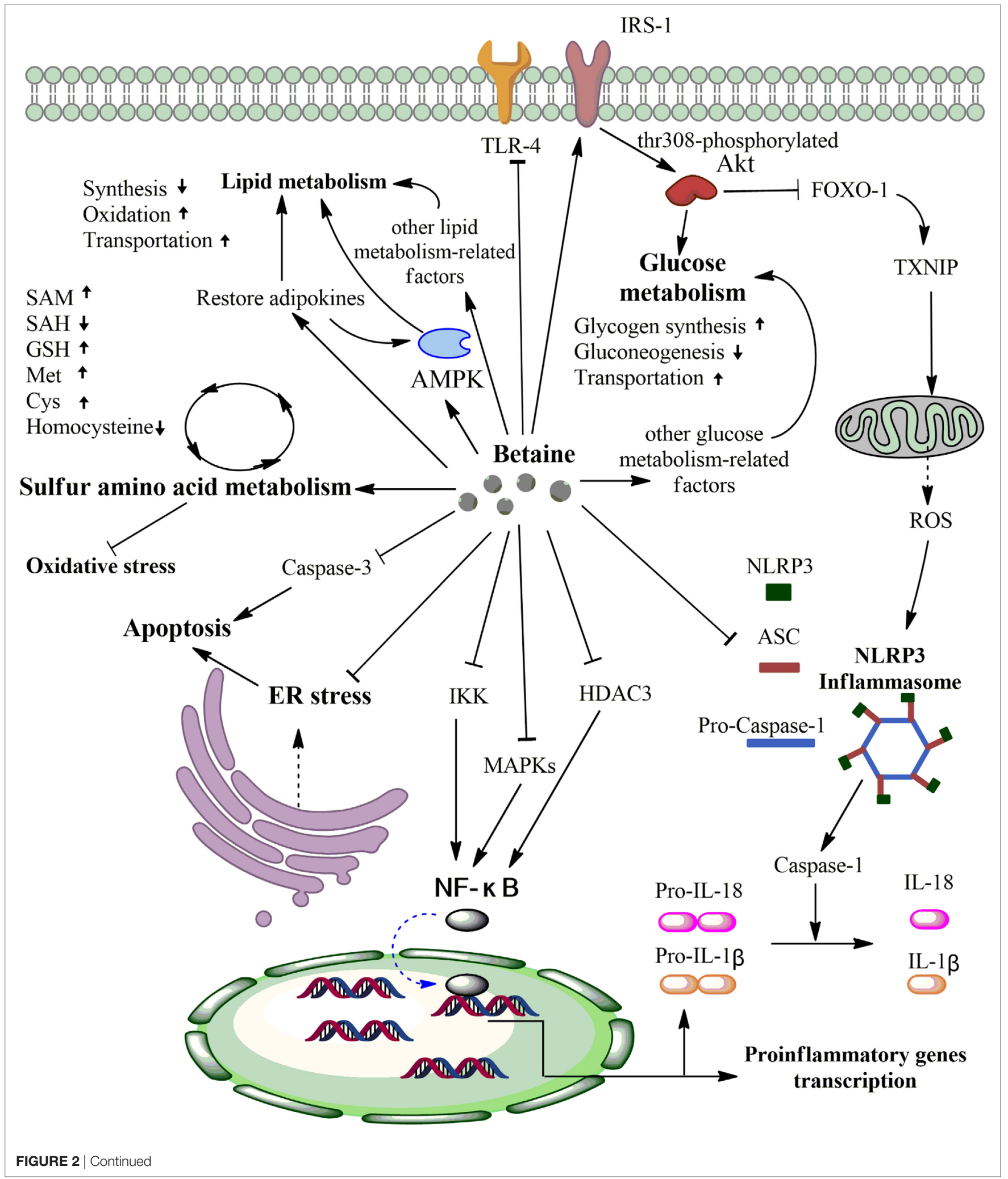


FIGURE 2 | Primary anti-inflammatory mechanisms of betaine. First, betaine can alter various sulfur amino acid (SAA) concentrations via protecting SAA metabolism from oxidative stress. Second, betaine can inhibit IKK, MAPKs, HDAC3, and Toll-like receptor-4 (TLR-4) activities to downregulate the nuclear factor- $\kappa B$ (NF- $\mathrm{KB}$ ) pathway and pro-inflammatory genes transcription. Third, betaine can reduce the expression levels of NLRP3 inflammation components (pro-caspase-1, ASC, and NLRP3) and inhibit the FOXO-1-induced NLRP3 inflammasome via enhancing the IRS/Akt pathway. Fourth, betaine significantly increases activated AMPK, restores adipokines that can activate AMPK, and activates other lipid metabolism-related factors to regulate lipid metabolism. Fifth, on the one hand, betaine increases phosphorylated IRS, which phosphorylates Akt at threonine 308, to improve glucose metabolism. On the other hand, betaine can influence other glucose metabolism-related factors to improve glucose metabolism. Sixth, betaine can inhibit caspase-3 to reduce apoptosis and repair endoplasmic reticulum (ER) stress. Akt, protein kinase B; AMPK, AMP-activated protein kinase; FOXO-1, forkhead box O1; TXNIP, thioredoxin-interacting protein; ROS, reactive oxygen species; IKK, nuclear factor-inducing kinase/lkB kinase; MAPKs, mitogen-activated protein kinases; HDAC3, histone deacetylases 3. SAM, S-adenosyl-L-methionine; SAH S-adenosyl-L-homocysteine; GSH, glutathione; Met, methionine; Cys, cysteine.

are contradictory. The current studies show that plasma betaine concentrations are inversely correlated with body fat percentages in adults; subjects with higher plasma betaine concentrations tended to have better fat profiles and distributions $(134,135)$. In a recent study, Gao and colleagues found that this positive correlation between plasma betaine concentrations and a better body composition existed in only males (144). Although this area deserves attention, there are few studies exploring the influence of betaine supplementation on obesity. In the studies of Schwab and Favero, betaine supplementation did not affect body composition $(145,146)$. However, in another study from Gao and colleagues, a large general population was analyzed, and a higher betaine intake was correlated with a better body composition (147). Similarly, other studies show that plasma betaine concentrations are inversely associated with human NAFLD, but the results of betaine supplementation are up for debate (148-152). Thus, in order to get the reliable result, more studies need to focus on this area from now on. In addition, many animal studies have shown that betaine is closely linked with diabetes $(12,153,154)$. Diabetes leads to hyperglycemia due to impaired glucose metabolism (155). Different from its role in obesity, plasma betaine concentration is a poor predictor for diagnosing diabetes in humans $(137,156,157)$. Nevertheless, plasma betaine concentration is likely linked with secondary diseases of diabetes, such as microangiopathy (158). Studies have shown that abnormal urinary betaine excretion is closely associated with diabetes (136-138), but its diagnostic value is lower than that of other substances, such as choline and DMG (159). Currently, only one study has investigated the effect of betaine supplementation on diabetes (160). Therefore, to identify whether betaine supplementation is effective, more systematic studies will be needed in the future. Various human studies have found that in addition to its association with metabolic diseases, betaine intake is associated with cancers, such as breast cancer, lung cancer, liver cancer, colorectal cancer, and nasopharyngeal carcinoma (139, 140, 161-163). In these studies, a higher betaine intake resulted in a lower risk of cancer. Furthermore, research has suggested that cancer incidence could be decreased by $11 \%$ by consuming choline plus betaine (100 mg/day) (164). However, in some studies, contradictory results have been found $(165,166)$. For example, Lee and colleagues found no association between colorectal cancer and betaine intake (165). So far, most of these have been case-control studies; to obtain reliable results, placebo-controlled intervention trials and prospective studies will be needed. Recently, a study has shown that betaine intervention could restore hyperhomocysteine, which is a hallmark of Alzheimer's disease (141), and attenuate the inflammatory reaction in Alzheimer's disease patients (167). This finding further extended the range of betaine applications in human diseases.

In summary, despite some contradictory results, we propose that betaine may have an application in treatment or ameliorating symptoms of various huaman inflammatory diseases because of betaine's significant anti-inflammatory effects (168). Notably, human diseases are undoubtedly more complex than animal disease models; therefore, to take advantage of the beneficial effects of betaine, researchers should continue to explore its mechanism and effects in humans.

\section{CONCLUSION}

In conclusion, this review discusses the major physiological role of betaine as an osmoprotectant and a methyl group donor, as well as the anti-inflammatory effects of betaine in various diseases. These effects are primarily associated with protecting SAA metabolism from oxidative stress, inhibiting NF- $\kappa \mathrm{B}$ and NLRP3 inflammasome activity, regulating energy metabolism, and mitigating ER stress and apoptosis (Figure 2). Although the data from animal experiments are compelling, the clinical situation appears to be much more complex than originally thought. For example, despite various animal studies reporting the effects of betaine supplementation and some mechanisms, human studies have shown contradictory results. Future studies should focus on both animal and clinical experiments to reduce errors from separate experiment types and to ensure the medicinal value of betaine. More importantly, it is worthwhile to further investigate betaine because its significant antiinflammatory effects could be beneficial for treating inflammatory diseases.

\section{AUTHOR CONTRIBUTIONS}

YP, WR, and GZ designed the review article, and GZ wrote the review article. YP and WR revised the review article. CW, FH, NL, JD, GZ, and PL helped with designing figures and finding relevant literature. YP and WR approved the final manuscript.

\section{FUNDING}

This work is supported by the earmarked fund of the China Agriculture Research System (Beef/Yak Cattle, CARS-37) and the Chongqing Science \& Technology Commission (cstc2016shmszx80085, cstc2017jcyjAX0288). 


\section{REFERENCES}

1. Yu D, Xu Z. Effects of betaine on growth performance and carcass characteristics in growing pigs. Asian-australas J Anim Sci (2004) 17(12):490-3. doi:10.5713/ajas.2004.1700

2. Craig SA. Betaine in human nutrition. Am J Clin Nutr (2004) 80(3):539. doi:10.1093/ajcn/80.3.539

3. Zeisel SH, Mar MH, Howe JC, Holden JM. Concentrations of cholinecontaining compounds and betaine in common foods. JNutr (2003) 133(5):1302-7. doi:10.1093/jn/133.5.1302

4. Zeisel SH. Metabolic crosstalk between choline/1-carbon metabolism and energy homeostasis. Clin Chem Lab Med (2013) 51(3):467-75. doi:10.1515/ cclm-2012-0518

5. Davies SE, Chalmers RA, Randall EW, Iles RA. Betaine metabolism in human neonates and developing rats. Clin Chim Acta (1988) 178(3):241-9. doi:10.1016/0009-8981(88)90232-X

6. Hoffmann L, Brauers G, Gehrmann T, Haussinger D, Mayatepek E, Schliess F, et al. Osmotic regulation of hepatic betaine metabolism. Am J Physiol Gastrointest Liver Physiol (2013) 304(9):G835-46. doi:10.1152/ ajpgi.00332.2012

7. Kempson SA, Vovor-Dassu K, Day C. Betaine transport in kidney and liver: use of betaine in liver injury. Cell Physiol Biochem (2013) 32(7):32-40. doi:10.1159/000356622

8. Geng CA, Ma YB, Zhang XM, Yao SY, Xue DQ, Zhang RP, et al. Mulberrofuran $\mathrm{G}$ and isomulberrofuran $\mathrm{G}$ from Morus alba L.: antihepatitis B virus activity and mass spectrometric fragmentation. J Agric Food Chem (2012) 60(33):8197. doi:10.1021/jf302639b

9. Zhang M, Wu X, Lai F, Zhang X, Wu H, Min T. Betaine inhibits hepatitis $B$ virus with an advantage of decreasing resistance to lamivudine and interferon $\alpha$. J Agric Food Chem (2016) 64(20):4068. doi:10.1021/acs.jafc. $6 \mathrm{~b} 01180$

10. Kathirvel E, Morgan K, Nandgiri G, Sandoval BC, Caudill MA, Bottiglieri T, et al. Betaine improves nonalcoholic fatty liver and associated hepatic insulin resistance: a potential mechanism for hepatoprotection by betaine. Am J Physiol Gastrointest Liver Physiol (2010) 299(5):G1068. doi:10.1152/ ajpgi.00249.2010

11. Jung YS, Sun JK, Kwon DY, Ahn CW, Kim YS, Choi DW, et al. Alleviation of alcoholic liver injury by betaine involves an enhancement of antioxidant defense via regulation of sulfur amino acid metabolism. Food Chem Toxicol (2013) 62(12):292-8. doi:10.1016/j.fct.2013.08.049

12. Kim DH, Kim SM, Lee B, Lee EK, Chung KW, Moon KM, et al. Effect of betaine on hepatic insulin resistance through FOXO1-induced NLRP3 inflammasome. J Nutr Biochem (2017) 45:104. doi:10.1016/j.jnutbio.2017. 04.014

13. Kettunen H, Peuranen S, Tiihonen K, Saarinen M. Intestinal uptake of betaine in vitro and the distribution of methyl groups from betaine, choline, and methionine in the body of broiler chicks. Comp Biochem Physiol A Mol Integr Physiol (2001) 128(2):269. doi:10.1016/S1095-6433(00)00301-9

14. Kettunen H, Tiihonen K, Peuranen S, Saarinen MT, Remus JC. Dietary betaine accumulates in the liver and intestinal tissue and stabilizes the intestinal epithelial structure in healthy and coccidia-infected broiler chicks. Comp Biochem Physiol A Mol Integr Physiol (2001) 130(4):759-69. doi:10.1016/ S1095-6433(01)00410-X

15. Lever M, Sizeland PC, Frampton CM, Chambers ST. Short and long-term variation of plasma glycine betaine concentrations in humans. Clin Biochem (2004) 37(3):184-90. doi:10.1016/j.clinbiochem.2003.11.004

16. Craig SS, Craig SA, Ganio MS, Maresh CM, Horrace G, Costa KAD, et al. The betaine content of sweat from adolescent females. J Int Soc Sports Nutr (2010) 7(1):3. doi:10.1186/1550-2783-7-3

17. Knight LS, Piibe Q, Lambie I, Perkins C, Yancey PH. Betaine in the brain: characterization of betaine uptake, its influence on other osmolytes and its potential role in neuroprotection from osmotic stress. Neurochem Res (2017) 42(12):3490-503. doi:10.1007/s11064-017-2397-3

18. Day CR, Kempson SA. Betaine chemistry, roles, and potential use in liver disease. Biochim Biophys Acta (2016) 1860(6):1098. doi:10.1016/j.bbagen. 2016.02.001

19. Yancey PH. Organic osmolytes as compatible, metabolic and counteracting cytoprotectants in high osmolarity and other stresses. JExp Biol (2005) 208(15):2819-30. doi:10.1242/jeb.01730
20. Neuhofer W, Beck FX. Cell survival in the hostile environment of the renal medulla. Annu Rev Physiol (2005) 67(67):531-55. doi:10.1146/annurev. physiol.67.031103.154456

21. Kempson SA, Zhou Y, Danbolt NC. The betaine/GABA transporter and betaine: roles in brain, kidney, and liver. Front Physiol (2014) 5(5):159. doi:10.3389/fphys.2014.00159

22. Dasgupta M, Kishore N. Selective inhibition of aggregation/fibrillation of bovine serum albumin by osmolytes: Mechanistic and energetics insights. Plos One (2017) 12(2):e0172208. doi:10.1371/journal.pone.0172208

23. Mcneil SD, Nuccio ML, Hanson AD. Betaines and related osmoprotectants. Targets for metabolic engineering of stress resistance. Plant Physiol (1999) 120(4):945-9. doi:10.1104/pp.120.4.945

24. Veis JH, Molitoris BA, Teitelbaum I, Mansour JA, Berl T. Myo-inositol uptake by rat cultured inner medullary collecting tubule cells: effect of osmolality. Am J Physiol (1991) 260(5 Pt 2):F619.

25. Bucolo C, Fidilio A, Cbm P, Geraci F, Lazzara F, Drago F. Antioxidant and osmoprotecting activity of taurine in dry eye models. Journal of Ocular Pharmacology \& Therapeutics the Official Journal of the Association for Ocular Pharmacology \& Therapeutics (2017) 34(1-2). doi:10.1089/jop. 2017.0008

26. Adamczak B, Wieczór M, Kogut M, Stangret J, Czub J. Molecular basis of the osmolyte effect on protein stability: lesson from the mechanical unfolding of lysozyme. Biochem J (2016) 473(20):3705-24. doi:10.1042/ BCJ20160604

27. Ratriyanto A, Mosenthin R, Bauer E, Eklund M. Metabolic, osmoregulatory and nutritional functions of betaine in monogastric animals. Asianaustralas J Anim Sci (2009) 22(10):1461-76. doi:10.5713/ajas.2009.80659

28. Horio M, Ito A, Matsuoka Y, Moriyama T, Orita Y, Takenaka M, et al. Apoptosis induced by hypertonicity in Madin Darley canine kidney cells: protective effect of betaine. Nephrol Dial Transplant (2001) 16(3):483-90. doi:10.1093/ndt/16.3.483

29. Zeisel S. Choline, other methyl-donors and epigenetics. Nutrients (2017) 9(5):445. doi:10.3390/nu9050445

30. Williams KT, Schalinske KL. New insights into the regulation of methyl group and homocysteine metabolism. J Nutr (2007) 137(2):311-4. doi:10.1093/jn/ 137.2.311

31. Ueland PM, Refsum H. Plasma homocysteine, a risk factor for vascular disease: plasma levels in health, disease, and drug therapy. J Lab Clin Med (1989) 114(5):473-501.

32. Barak AJ, Beckenhauer HC, Tuma DJ. Betaine, ethanol, and the liver: a review. Alcohol (1996) 13(4):395-8. doi:10.1016/0741-8329(96)00030-4

33. Yamamoto A, Takagi H, Kitamura D, Tatsuoka H, Nakano H, Kawano H, et al. Deficiency in protein L-isoaspartyl methyltransferase results in a fatal progressive epilepsy. JNeurosci (1998) 18(6):2063-74. doi:10.1523/ JNEUROSCI.18-06-02063.1998

34. Nishimakimogami T, Yao Z, Fujimori K. Inhibition of phosphatidylcholine synthesis via the phosphatidylethanolamine methylation pathway impairs incorporation of bulk lipids into VLDL in cultured rat hepatocytes. J Lipid Res (2002) 43(7):1035-45. doi:10.1194/jlr.M100354-JLR200

35. Boisvert FM, Côté J, Boulanger MC, Richard S. A proteomic analysis of arginine-methylated protein complexes. Mol Cell Proteomics (2003) 2(12):1319. doi:10.1074/mcp.M300088-MCP200

36. Rando RR. Chemical biology of isoprenylation/methylation. Biochem Soc Trans (1996) 24(3):682. doi:10.1042/bst0240682

37. Kramer K, Harrington EO, Lu Q, Bellas R, Newton J, Sheahan KL, et al. Isoprenylcysteine carboxyl methyltransferase activity modulates endothelial cell apoptosis. Mol Biol Cell (2003) 14(3):848. doi:10.1091/mbc.E0207-0390

38. Kim DI, Park MJ, Lim SK, Park JI, Yoon KC, Han HJ, et al. PRMT3 regulates hepatic lipogenesis through direct interaction with LXR $\alpha$. Diabetes (2015) 64(1):60. doi:10.2337/db13-1394

39. Mosharov E, Cranford MR, Banerjee R. The quantitatively important relationship between homocysteine metabolism and glutathione synthesis by the transsulfuration pathway and its regulation by redox changes. Biochemistry (2000) 39(42):13005-11. doi:10.1021/bi001088w

40. Jung YS, Kwak HE, Choi KH, Kim YC. Effect of acute ethanol administration on S-amino acid metabolism: increased utilization of cysteine for synthesis of taurine rather than glutathione. Adv Exp Med Biol (2003) 526:245. doi:10.1007/978-1-4615-0077-3_31 
41. Meng B, Gao W, Wei J, Yang J, Wu J, Pu L, et al. Quercetin reduces serum homocysteine level in rats fed a methionine-enriched diet. Nutrition (2013) 29(4):661-6. doi:10.1016/j.nut.2012.10.012

42. Cholewa JM, Guimarães-Ferreira L, Zanchi NE. Effects of betaine on performance and body composition: a review of recent findings and potential mechanisms. Amino Acids (2014) 46(8):1785. doi:10.1007/s00726014-1748-5

43. Lawsonyuen A, Levy HL. The use of betaine in the treatment of elevated homocysteine. Mol Genet Metab (2006) 88(3):201-7. doi:10.1016/j.ymgme. 2006.02.004

44. Jin Z, Mendu SK, Birnir B. GABA is an effective immunomodulatory molecule. Amino Acids (2013) 45(1):87-94. doi:10.1007/s00726-011-1193-7

45. Sies H. Oxidative stress: oxidants and antioxidants. Exp Physiol (1997) 82(2):291-5. doi:10.1113/expphysiol.1997.sp004024

46. Davies KJ. Oxidative stress: the paradox of aerobic life. Biochem Soc Symp (1995) 61:1-31. doi:10.1042/bss0610001

47. Tsai MC, Huang TL. Increased activities of both superoxide dismutase and catalase were indicators of acute depressive episodes in patients with major depressive disorder. Psychiatry Research (2015) 235:38-42. doi:10.1016/j. psychres.2015.12.005

48. Tan DX, Manchester LC, Terron MP, Flores LJ, Reiter RJ. One molecule, many derivatives: a never-ending interaction of melatonin with reactive oxygen and nitrogen species? J Pineal Res (2007) 42(1):28-42. doi:10.1111/ j.1600-079X.2006.00407.x

49. Dumaswala UJ, Zhuo L, Mahajan S, Nair PN, Shertzer HG, Dibello P, et al. Glutathione protects chemokine-scavenging and antioxidative defense functions in human RBCs. Am J Physiol Cell Physiol (2001) 280(4):C867. doi:10.1152/ajpcell.2001.280.4.C867

50. Freitas I, Boncompagni E, Tarantola E, Gruppi C, Bertone V, Ferrigno A, et al. In situ evaluation of oxidative stress in rat fatty liver induced by a methionineand choline-deficient diet. Oxid Med Cell Longev (2016) 2016(3):9307064. doi:10.1155/2016/9307064

51. Zhang B, Dong JL, Chen YL, Liu Y, Huang SS, Zhong XL, et al. Nrf2 mediates the protective effects of homocysteine by increasing the levels of GSH content in HepG2 cells. Mol Med Rep (2017) 16(1):597. doi:10.3892/ mmr.2017.6633

52. Almashhadany A, Shackebaei D, Van der Touw T, Jones GL, Suleiman MS, King N. Homocysteine exposure impairs myocardial resistance to ischaemia reperfusion and oxidative stress. Cell Physiol Biochem (2015) 37(6):2265-74. doi: $10.1159 / 000438582$

53. Baggott JE, Tamura T. Homocysteine, iron and cardiovascular disease: a hypothesis. Nutrients (2015) 7(2):1108-18. doi:10.3390/nu7021108

54. Barak AJ, Beckenhauer HC, Badakhsh S, Tuma DJ. The effect of betaine in reversing alcoholic steatosis. Alcohol Clin Exp Res (1997) 21(6):1100-2. doi:10.1111/j.1530-0277.1997.tb04259.x

55. Ji C, Kaplowitz N. Betaine decreases hyperhomocysteinemia, endoplasmic reticulum stress, and liver injury in alcohol-fed mice. Gastroenterology (2003) 124(5):1488. doi:10.1016/S0016-5085(03)00276-2

56. Shinohara M, Ji CN. Differences in betaine-homocysteine methyltransferase expression, endoplasmic reticulum stress response, and liver injury between alcohol-fed mice and rats. Hepatology (2010) 51(3):796. doi:10.1002/hep.23391

57. RC P, Swarup D, Dwivedi SK. Antioxidant effects of alpha tocopherol, ascorbic acid and L-methionine on lead induced oxidative stress to the liver, kidney and brain in rats. Toxicology (2001) 162(2):81. doi:10.1016/ S0300-483X(01)00345-6

58. Martínez Y, Li X, Liu G, Bin P, Yan W, Más D, et al. The role of methionine on metabolism, oxidative stress, and diseases. Amino Acids (2017) 49(12):2091-8. doi:10.1007/s00726-017-2494-2

59. Pastor A, Collado PS, Almar M, Gonzálezgallego J. Microsomal function in biliary obstructed rats: effects of S-adenosylmethionine. J Hepatol (1996) 24(3):353-9. doi:10.1016/S0168-8278(96)80016-X

60. Cavallaro RA, Fuso A, Nicolia V, Scarpa S. S-adenosylmethionine prevents oxidative stress and modulates glutathione metabolism in TgCRND8 mice fed a B-vitamin deficient diet. J Alzheimers Dis (2010) 20(4):997. doi:10.3233/ JAD-2010-091666

61. Barak AJ, Beckenhauer HC, Mailliard ME, Kharbanda KK, Tuma DJ. Betaine lowers elevated s-adenosylhomocysteine levels in hepatocytes from ethanol-fed rats. J Nutr (2003) 133(9):2845-8. doi:10.1093/jn/133.9.2845
62. Tehlivets $\mathrm{O}$. Homocysteine as a risk factor for atherosclerosis: is its conversion to s-adenosyl-L-homocysteine the key to deregulated lipid metabolism? J Lipids (2011) 2011(2011):702853. doi:10.1155/2011/702853

63. Kwon DY, Jung YS, Kim SJ, Park HK, Park JH, Kim YC. Impaired sulfur-amino acid metabolism and oxidative stress in nonalcoholic fatty liver are alleviated by betaine supplementation in rats. J Nutr (2009) 139(1):63. doi:10.3945/jn.108.094771

64. Kharbanda KK, Todero SL, King AL, Osna NA, Mcvicker BL, Tuma DJ, et al. Betaine treatment attenuates chronic ethanol-induced hepatic steatosis and alterations to the mitochondrial respiratory chain proteome. Int $J$ Hepatol (2011) 2012(16):962183. doi:10.1155/2012/962183

65. Fernández-Checa JC, Colell A, García-Ruiz C. S-adenosyl-L-methionine and mitochondrial reduced glutathione depletion in alcoholic liver disease. Alcohol (2002) 27(3):179-83. doi:10.1016/S0741-8329(02)00229-X

66. Kim SJ, Jung YS, Kwon DY, Kim YC. Alleviation of acute ethanol-induced liver injury and impaired metabolomics of S-containing substances by betaine supplementation. Biochem Biophys Res Commun (2008) 368(4):893. doi:10.1016/j.bbrc.2008.02.003

67. Bingül İ, Aydın AF, Başaran-Küçükgergin C, Doğan-Ekici I, Çoban J, Doğru-Abbasoğlu S, et al. High-fat diet plus carbon tetrachloride-induced liver fibrosis is alleviated by betaine treatment in rats. Int Immunopharmacol (2016) 39:199. doi:10.1016/j.intimp.2016.07.028

68. Bingül İ, Başaranküçükgergin C, Aydın AF, Çoban J, Doğanekici I, Doğruabbasoğlu $S$, et al. Betaine treatment decreased oxidative stress, inflammation, and stellate cell activation in rats with alcoholic liver fibrosis. Environ Toxicol Pharmacol (2016) 45:170. doi:10.1016/j.etap.2016.05.033

69. He F, Wu C, Li P, Li N, Zhang D, Zhu Q, et al. Functions and signaling pathways of amino acids in intestinal inflammation. Biomed Res Int (2018). 2018(3):1-13. doi:10.1155/2018/9171905

70. Ron D. Hyperhomocysteinemia and function of the endoplasmic reticulum. J Clin Invest (2001) 107(10):1221-2. doi:10.1172/JCI13092

71. Pompella A, Corti A. Editorial: the changing faces of glutathione, a cellular protagonist. Biochem Pharmacol (2003) 66(8):1499. doi:10.1016/S00062952(03)00504-5

72. Monaco C, Andreakos E, Kiriakidis S, Mauri C, Bicknell C, Foxwell B, et al. Canonical pathway of nuclear factor kappa B activation selectively regulates proinflammatory and prothrombotic responses in human atherosclerosis. ProcNatlAcad Sci USA (2004) 101(15):5634-9. doi:10.1073/pnas.0401060101

73. Aravilli RK, Vikram SL, Kohila V. Phytochemicals as potential antidotes for targeting NF- $\mathrm{KB}$ in rheumatoid arthritis. 3 Biotech (2017) 7(4):253. doi:10.1007/s13205-017-0888-1

74. Schuliga M. NF-kappaB signaling in chronic inflammatory airway disease. Biomolecules (2015) 5(3):1266-83. doi:10.3390/biom5031266

75. Go EK, Jung KJ, Kim JY, Yu BP, Chung HY. Betaine suppresses proinflammatory signaling during aging: the involvement of nuclear factor-kappaB via nuclear factor-inducing kinase/IkappaB kinase and mitogen-activated proteinkinases.J Gerontol(2005)60(10):1252.doi:10.1093/gerona/60.10.1252

76. Lee EK, Jang EJ, Jung KJ, Kim DH, Yu BP, Chung HY. Betaine attenuates lysophosphatidylcholine-mediated adhesion molecules in aged rat aorta: modulation of the nuclear factor-кB pathway. Exp Gerontol (2013) 48(5):517. doi:10.1016/j.exger.2013.02.024

77. Yi EY, Kim YJ. Betaine inhibits in vitro and in vivo angiogenesis through suppression of the NF-kappaB and Akt signaling pathways. Int J Oncol (2012) 41(5):1879-85. doi:10.3892/ijo.2012.1616

78. Je JH, Lee JY, Jung KJ, Sung B, Go EK, Yu BP, et al. NF-kappaB activation mechanism of 4-hydroxyhexenal via NIK/IKK and p38 MAPK pathway. FEBS Lett (2004) 566(1-3):183-9. doi:10.1016/j.febslet.2004.04.037

79. Kyriakis JM, Avruch J. Mammalian MAPK signal transduction pathways activated by stress and inflammation: a 10-year update. Physiol Rev (2012) 92(2):689. doi:10.1152/physrev.00028.2011

80. Go EK, Jung KJ, Kim JM, Lim H, Lim HK, Yu BP, et al. Betaine modulates age-related NF- $\kappa B$ by thiol-enhancing action. Biol Pharm Bull (2007) 30(12):2244-9. doi:10.1248/bpb.30.2244

81. Kim DH, Sung B, Kang YJ, Jang JY, Hwang SY, Lee Y, et al. Anti-inflammatory effects of betaine on AOM/DSS-induced colon tumorigenesis in ICR male mice. Int J Oncol (2014) 45(3):1250. doi:10.3892/ijo.2014.2515

82. Li JM, Ge CX, Xu MX, Wang W, Yu R, Fan CY, et al. Betaine recovers hypothalamic neural injury by inhibiting astrogliosis and inflammation in 
fructose-fed rats. Mol Nutr Food Res (2015) 59(2):189-202. doi:10.1002/ mnfr.201400307

83. Zhang W, Wang LW, Wang LK, Li X, Zhang H, Luo LP, et al. Betaine protects against high-fat-diet-induced liver injury by inhibition of high-mobility group box 1 and Toll-like receptor 4 expression in rats. Dig Dis Sci (2013) 58(11):3198. doi:10.1007/s10620-013-2775-x

84. Sims JE, Smith DE. The IL-1 family: regulators of immunity. Nat Rev Immunol (2010) 10(2):89. doi:10.1038/nri2691

85. Martinon F, Mayor A, Tschopp J. The inflammasomes: guardians of the body. Annu Rev Immunol (2009) 27(27):229. doi:10.1146/annurev.immunol. 021908.132715

86. Lordnejad MR, Schliess F, Wettstein M, Haussinger D. Modulation of the heme oxygenase HO-1 expression by hyperosmolarity and betaine in primary rat hepatocytes. Arch Biochem Biophys (2001) 388(2):285-92. doi:10.1006/abbi.2001.2297

87. Graf D, Kurz AK, Reinehr R, Fischer R, Kircheis G, Häussinger D. Prevention of bile acid-induced apoptosis by betaine in rat liver. Hepatology (2002) 36(4):829-39. doi:10.1053/jhep.2002.35536

88. Kim SJ, Lee SM. NLRP3 inflammasome activation in D-galactosamine and lipopolysaccharide-induced acute liver failure: role of heme oxygenase-1. Free Radic Biol Med (2013) 65(4):997. doi:10.1016/j.freeradbiomed.2013.08.178

89. Ge CX, Yu R, Xu MX, Li PQ, Fan CY, Li JM, et al. Betaine prevented fructose-induced NAFLD by regulating LXR $\alpha /$ PPAR $\alpha$ pathway and alleviating ER stress in rats. Eur J Pharmacol (2016) 770:154-64. doi:10.1016/j. ejphar.2015.11.043

90. Fan CY, Wang MX, Ge CX, Wang X, Li JM, Kong LD. Betaine supplementation protects against high-fructose-induced renal injury in rats. J Nutr Biochem (2014) 25(3):353. doi:10.1016/j.jnutbio.2013.11.010

91. Van Der Heide LP, Hoekman MF, Smidt MP. The ins and outs of FoxO shuttling: mechanisms of FoxO translocation and transcriptional regulation. Biochem J (2004) 380(2):297-309. doi:10.1042/bj20040167

92. Accili D, Arden KC. FoxOs at the crossroads of cellular metabolism, differentiation, and transformation. Cell (2004) 117(4):421-6. doi:10.1016/ S0092-8674(04)00452-0

93. Li X, Rong Y, Zhang M, Wang XL, Lemaire SA, Coselli JS, et al. Up-regulation of thioredoxin interacting protein (Txnip) by p38 MAPK and FOXO1 contributes to the impaired thioredoxin activity and increased ROS in glucose-treated endothelial cells. Biochem Biophys Res Commun (2009) 381(4):660-5. doi:10.1016/j.bbrc.2009.02.132

94. Wang Y, Zhou Y, Graves DT. FOXO transcription factors: their clinical significance and regulation. Biomed Res Int (2014) 2014(3):925350. doi:10.1155/2014/925350

95. Sik CS, Young HJ, Jae HI, In KJ, Bum KJ. Adipose tissue remodeling: its role in energy metabolism and metabolic disorders. Front Endocrinol (2016) 7:30. doi: $10.3389 /$ fendo. 2016.00030

96. Li S, Wang H, Wang X, Wang Y, Feng J. Betaine affects muscle lipid metabolism via regulating the fatty acid uptake and oxidation in finishing pig. J Anim Sci Biotechnol (2017) 8(1):72. doi:10.1186/s40104-017-0200-6

97. Xu L, Huang D, Hu Q, Wu J, Wang Y, Feng J. Betaine alleviates hepatic lipid accumulation via enhancing hepatic lipid export and fatty acid oxidation in rats fed with a high-fat diet. Br J Nutr (2015) 113(12):1835-43. doi:10.1017/ S0007114515001130

98. Song Z, Deaciuc I, Zhou Z, Song M, Chen T, Hill D, et al. Involvement of AMP-activated protein kinase in beneficial effects of betaine on high-sucrose diet-induced hepatic steatosis. Am J Physiol Gastrointest Liver Physiol (2007) 293(4):G894. doi:10.1152/ajpgi.00133.2007

99. Du J, Shen L, Tan Z, Zhang P, Zhao X, Xu Y, et al. Betaine supplementation enhances lipid metabolism and improves insulin resistance in mice fed a high-fat diet. Nutrients (2018) 10(2). doi:10.3390/nu10020131

100. Yang Z, Hu X, Liu Y, Dong S, Wen Z, He W, et al. ROS signaling under metabolic stress: cross-talk between AMPK and AKT pathway. Mol Cancer (2017) 16(1):79. doi:10.1186/s12943-017-0648-1

101. Li Y, Xu S, Mihaylova M, Zheng B, Hou X, Jiang B, et al. AMPK phosphorylates and inhibits SREBP activity to attenuate hepatic steatosis and atherosclerosis in diet-induced insulin resistant mice. Cell Metab (2011) 13(4):376-88. doi:10.1016/j.cmet.2011.03.009

102. Russell RR III, Bergeron R, Shulman GI, Young LH. Translocation of myocardial GLUT-4 and increased glucose uptake through activation of AMPK by AICAR. Am J Physiol (1999) 277(2):643-9.
103. Sang-Min J. Regulation and function of AMPK in physiology and diseases. Exp Mol Med (2016) 48(7):e245. doi:10.1038/emm.2016.81

104. Huypens P, Moens K, Heimberg H, Ling Z, Pipeleers D, Van de Casteele M. Adiponectin-mediated stimulation of AMP-activated protein kinase (AMPK) in pancreatic beta cells. Life Sci (2005) 77(11):1273-82. doi:10.1016/j. lfs.2005.03.008

105. Bonnard C, Durand A, Vidal H, Rieusset J. Changes in adiponectin, its receptors and AMPK activity in tissues of diet-induced diabetic mice. Diabetes Metab (2008) 34(1):52-61. doi:10.1016/j.diabet.2007.09.006

106. Olli K, Lahtinen S, Rautonen N, Tiihonen K. Betaine reduces the expression of inflammatory adipokines caused by hypoxia in human adipocytes. Br J Nutr (2013) 109(1):43-9. doi:10.1017/S0007114512000888

107. Wang Z, Yao T, Pini M, Zhou Z, Fantuzzi G, Song Z. Betaine improved adipose tissue function in mice fed a high-fat diet: a mechanism for hepatoprotective effect of betaine in nonalcoholic fatty liver disease. Am J Physiol Gastrointest Liver Physiol (2010) 298(5):G634. doi:10.1152/ajpgi.00249.2009

108. Wang L, Chen L, Tan Y, Wei J, Chang Y, Jin T, et al. Betaine supplement alleviates hepatic triglyceride accumulation of apolipoprotein $\mathrm{E}$ deficient mice via reducing methylation of peroxisomal proliferator-activated receptor alpha promoter. Lipids Health Dis (2013) 12(1):34. doi:10.1186/ 1476-511X-12-34

109. Kim DH, Lee B, Min HP, Min JK, An HJ, Lee EK, et al. Molecular mechanism of betaine on hepatic lipid metabolism: inhibition of FoxO1 binding to PPARg. JAgric Food Chem (2016) 64(36):6819. doi:10.1021/acs.jafc. $6 \mathrm{~b} 02644$

110. Hagar H, Medany AE, Salam R, Medany GE, Nayal OA. Betaine supplementation mitigates cisplatin-induced nephrotoxicity by abrogation of oxidative/nitrosative stress and suppression of inflammation and apoptosis in rats. Exp Toxicol Pathol (2015) 67(2):133-41. doi:10.1016/j.etp.2014. 11.001

111. Kharbanda KK, Todero SL, Ward BW, Tuma DJ. Betaine administration corrects ethanol-induced defective VLDL secretion. Mol Cell Biochem (2009) 327(1-2):75-8. doi:10.1007/s11010-009-0044-2

112. Huang LS, Voyiaziakis E, Markenson DF, Sokol KA, Hayek T, Breslow JL. apo $B$ gene knockout in mice results in embryonic lethality in homozygotes and neural tube defects, male infertility, and reduced HDL cholesterol ester and apo A-I transport rates in heterozygotes. J Clin Invest (1995) 96(5):2152-61. doi:10.1172/JCI1 18269

113. Wellen KE, Hotamisligil GS. Inflammation, stress, and diabetes. J Clin Invest (2005) 115(5):1111-9. doi:10.1172/JCI200525102

114. Barazzoni R, Gortan Cappellari G, Ragni M, Nisoli E. Insulin resistance in obesity: an overview of fundamental alterations. Eat Weight Disord (2018) 23(2):149-57. doi:10.1007/s40519-018-0481-6

115. Schultze SM, Hemmings BA, Markus N, Oliver T. PI3K/AKT, MAPK and AMPK signalling: protein kinases in glucose homeostasis. Exp Rev Mol Med (2012) 14:e1. doi:10.1017/S1462399411002109

116. Song G, Ouyang G, Bao S. The activation of Akt/PKB signaling pathway and cell survival. J Cell Mol Med (2005) 9(1):59-71. doi:10.1111/j.1582-4934.2005. tb00337.x

117. Burgess SC, He TT, Yan Z, Lindner J, Sherry AD, Malloy CR, et al. Cytosolic phosphoenolpyruvate carboxykinase does not solely control the rate of hepatic gluconeogenesis in the intact mouse liver. Cell Metab (2007) 5(4):313. doi:10.1016/j.cmet.2007.03.004

118. Plyte SE, Hughes K, Nikolakaki E, Pulverer BJ, Woodgett JR. Glycogen synthase kinase-3: functions in oncogenesis and development. Biochim Biophys Acta (1992) 1114(2-3):147-62. doi:10.1016/0304-419X(92)90012-N

119. Iwasaki H. Impaired PRMT1 activity in the liver and pancreas of type 2 diabetic Goto-Kakizaki rats. Life Sci (2009) 85(3-4):161. doi:10.1016/j. lfs.2009.05.007

120. Iwasaki H. Involvement of PRMT1 in hnRNPQ activation and internalization of insulin receptor. Biochem Biophys Res Commun (2008) 372(2):314-9. doi:10.1016/j.bbrc.2008.05.051

121. Iwasaki H, Yada T. Protein arginine methylation regulates insulin signaling in L6 skeletal muscle cells. Biochem Biophys Res Commun (2007) 364(4):1015. doi:10.1016/j.bbrc.2007.10.113

122. Sparks JD, Collins HL, Chirieac DV, Cianci J, Jokinen J, Sowden MP, et al. Hepatic VLDL and apolipoprotein B production are increased following in vivo induction of betaine-homocysteine S-methyltransferase. Biochem J (2006) 395(2):363-71. doi:10.1042/BJ20051966 
123. Cross DAE, Alessi DR, Cohen P, Andjelkovich M, Hemmings BA. Inhibition of glycogen synthase kinase-3 by insulin mediated by protein kinase B. Nature (1995) 378(6559):785-9. doi:10.1038/378785a0

124. Matsumoto M, Pocai A, Rossetti L, Depinho RA, Accili D. Impaired regulation of hepatic glucose production in mice lacking the forkhead transcription factor Foxo1 in liver. Cell Metab (2007) 6(3):208-16. doi:10.1016/j. cmet.2007.08.006

125. Zhou Y, Lee J, Reno CM, Sun C, Sang WP, Chung J, et al. Regulation of glucose homeostasis through a XBP-1-FoxO1 interaction. Nat Med (2011) 17(3):356-65. doi:10.1038/nm.2293

126. Schröder M, Kaufman RJ.ER stress and the unfolded protein response. Mutat Res (2005) 569(1):29-63. doi:10.1016/j.mrfmmm.2004.06.056

127. Zheng YZ, Cao ZG, Hu X, Shao ZM. The endoplasmic reticulum stress markers GRP78 and CHOP predict disease-free survival and responsiveness to chemotherapy in breast cancer. Breast Cancer Res Treat (2014) 145(2):349-58. doi:10.1007/s10549-014-2967-x

128. Kondylis V, Kumari S, Vlantis K, Pasparakis M. The interplay of IKK, NF-kB and RIPK1 signaling in the regulation of cell death, tissue homeostasis and inflammation. Immunol Rev (2017) 277(1):113. doi:10.1111/imr.12550

129. Larsen BD, Rampalli S, Burns LE, Brunette S, Dilworth FJ, Megeney LA. Caspase 3/caspase-activated DNase promote cell differentiation by inducing DNA strand breaks. Proc Natl Acad Sci U S A (2010) 107(9):4230-5. doi:10.1073/pnas.0913089107

130. Ji C, Shinohara M, Kuhlenkamp J, Chan C, Kaplowitz N. Mechanisms of protection by the betaine-homocysteine methyltransferase/betaine system in HepG2 cells and primary mouse hepatocytes. Hepatology (2010) 46(5):1586-96. doi:10.1002/hep.21854

131. Gaur N, Karouzakis E, Glück S, Bagdonas E, Jüngel A, Michel BA, et al. MicroRNAs interfere with DNA methylation in rheumatoid arthritis synovial fibroblasts. RMD Open (2016) 2(2):e000299. doi:10.1136/rmdopen2016-000299

132. Kharbanda KK, Rogers DD II, Mailliard ME, Siford GL, Barak AJ, Beckenhauer HC, et al. Role of elevated S-adenosylhomocysteine in rat hepatocyte apoptosis: protection by betaine. Biochem Pharmacol (2005) 70(12):1883-90. doi:10.1016/j.bcp.2005.09.021

133. Garrett Q, Khandekar N, Shih S, Flanagan JL, Simmons P, Vehige J, et al. Betaine stabilizes cell volume and protects against apoptosis in human corneal epithelial cells under hyperosmotic stress. Exp Eye Res (2013) 108(3):33-41. doi:10.1016/j.exer.2012.12.001

134. Konstantinova SV, Tell GS, Vollset SE, Nygård O, Bleie Ø, Ueland PM. Divergent associations of plasma choline and betaine with components of metabolic syndrome in middle age and elderly men and women. J Nutr (2008) 138(5):914. doi:10.1093/jn/138.5.914

135. Chen YM, Liu Y, Liu YH, Wang X, Guan K, Zhu HL. Higher serum concentrations of betaine rather than choline is associated with better profiles of DXA-derived body fat and fat distribution in Chinese adults. Int J Obes (2014) 39(3):465. doi:10.1038/ijo.2014.158

136. Schartumhansen H, Ueland PM, Pedersen ER, Meyer K, Ebbing M, Bleie Ø, et al. Assessment of urinary betaine as a marker of diabetes mellitus in cardiovascular patients. PLoS One (2013) 8(8):e69454. doi:10.1371/journal. pone. 0069454

137. Lever M, Slow S, Mcgregor DO, Dellow WJ, George PM, Chambers ST. Variability of plasma and urine betaine in diabetes mellitus and its relationship to methionine load test responses: an observational study. Cardiovasc Diabetol (2012) 11(1):34. doi:10.1186/1475-2840-11-34

138. Dellow WJ, Chambers ST, Lever M, Lunt H, Robson RA. Elevated glycine betaine excretion in diabetes mellitus patients is associated with proximal tubular dysfunction and hyperglycemia. Diabetes Res Clin Pract (1999) 43(2):91-9. doi:10.1016/S0168-8227(98)00115-6

139. Ying J, Rahbar MH, Hallman DM, Hernandez LM, Spitz MR, Forman MR, et al. Associations between dietary intake of choline and betaine and lung cancer risk. PLoS One (2013) 8(2):e54561. doi:10.1371/journal.pone. 0054561

140. Zeng F, Xu C, Liu Y, Fan Y, Lin X, Lu Y, et al. Choline and betaine intakes are associated with reduced risk of nasopharyngeal carcinoma in adults: a case-control study. Br J Cancer (2014) 110(3):808. doi:10.1038/bjc.2013.686

141. Madsen SK, Rajagopalan P, Joshi SH, Toga AW, Thompson PM. Higher homocysteine associated with thinner cortical gray matter in 803 participants from the Alzheimer's disease neuroimaging initiative. Neurobiol Aging (2015) 36:S203-10. doi:10.1016/j.neurobiolaging.2014.01.154

142. Huang QC, Xu ZR, Han XY, Li WF. Changes in hormones, growth factor and lipid metabolism in finishing pigs fed betaine-livestock science. Livest Sci (2006) 105(1):78-85. doi:10.1016/j.livsci.2006.04.031

143. He S, Zhao S, Dai S, Liu D, Bokhari SG. Effects of dietary betaine on growth performance, fat deposition and serum lipids in broilers subjected to chronic heat stress. Anim Sci J (2015) 86(10):897. doi:10.1111/asj.12372

144. Gao X, Randell E, Zhou H, Sun G. Higher serum choline and betaine levels are associated with better body composition in male but not female population. PLoS One (2018) 13(2):e0193114. doi:10.1371/journal.pone.0193114

145. Schwab U, Törrönen A, Toppinen L, Alfthan G, Saarinen M, Aro A, et al. Betaine supplementation decreases plasma homocysteine concentrations but does not affect body weight, body composition, or resting energy expenditure in human subjects. Am J Clin Nutr (2002) 76(5):961. doi:10.1093/ajcn/76.5.961

146. Favero SD, Roschel H, Artioli G, Ugrinowitsch C, Tricoli V, Costa A, et al. Creatine but not betaine supplementation increases muscle phosphorylcreatine content and strength performance. Amino Acids (2012) 42(6): 2299-305. doi:10.1007/s00726-011-0972-5

147. Gao X, Wang Y, Edward R, Pardis P, Yi Y, Wayne G, et al. Higher dietary choline and betaine intakes are associated with better body composition in the adult population of Newfoundland, Canada. PLoS One (2016) 11(5):e0155403. doi:10.1371/journal.pone. 0155403

148. Sookoian S, Puri P, Castaño GO, Scian R, Mirshahi F, Sanyal AJ, et al. Nonalcoholic steatohepatitis is associated with a state of betaine-insufficiency. Liver Int (2016) 150(4):S1140-1. doi:10.1111/liv.13249

149. Chen YM, Liu Y, Zhou RF, Chen XL, Wang C, Tan XY, et al. Associations of gut-flora-dependent metabolite trimethylamine- $\mathrm{N}$-oxide, betaine and choline with non-alcoholic fatty liver disease in adults. Sci Rep (2016) 6:19076. doi:10.1038/srep19076

150. Miglio F, Rovati LC, Santoro A, Setnikar I. Efficacy and safety of oral betaine glucuronate in non-alcoholic steatohepatitis. A double-blind, randomized, parallel-group, placebo-controlled prospective clinical study. Arzneimittelforschung (2000) 50(8):722-7. doi:10.1055/s-0031-1300279

151. Abdelmalek MF, Soangulo S. Betaine for nonalcoholic fatty liver disease: results of a randomized placebo-controlled trial. Hepatology (2009) 50(6):1818-26. doi:10.1002/hep.23239

152. Tiihonen K, Saarinen MT, Alhoniemi E, Mitsuya N, Yamaki G. Effect of dietary betaine on metabolic syndrome risk factors in Asian males with mild fatty liver. Journal of Diabetes and Metabolism (2016) 7:692. doi:10.4172/2155-6156.1000692

153. Jung GY, Won SB, Kim J, Jeon S, Han A, Kwon YH. Betaine Alleviates Hypertriglycemia and Tau Hyperphosphorylation in $\mathrm{db} / \mathrm{db}$ Mice. Toxicological Research (2013) 29(1):7. doi:10.5487/TR.2013.29.1.007

154. Kim YG, Lim HH, Lee SH, Shin MS, Kim CJ, Yang HJ. Betaine inhibits vascularization via suppression of Akt in the retinas of streptozotocininduced hyperglycemic rats. Mol Med Rep (2015) 12(2):1639. doi:10.3892/ mmr.2015.3613

155. Kitabchi AE, Umpierrez GE, Miles JM, Fisher JN. Hyperglycemic crises in adult patients with diabetes. Diabetes Care (2009) 32(12):e157; author reply e8. doi:10.2337/dc09-9032

156. Lever M, Sizeland PCB, Bason LM, Hayman CM, Robson RA, Chambers ST. Abnormal glycine betaine content of the blood and urine of diabetic and renal patients. Clin Chim Acta (1994) 230(1):69. doi:10.1016/0009-8981(94) 90090-6

157. Dullaart RPF, Erwin G, Elias J, Gruppen EG, Connelly MA. Plasma phospholipid transfer protein activity is inversely associated with betaine in diabetic and non-diabetic subjects. Lipids Health Dis (2016) 15(1):143. doi:10.1186/ s12944-016-0313-5

158. Chen L, Chen YM, Wang LJ, Wei J, Tan YZ, Zhou JY, et al. Higher homocysteine and lower betaine increase the risk of microangiopathy in patients with diabetes mellitus carrying the GG genotype of PEMT G774C. Diabetes Metab Res Rev (2013) 29(8):607-17. doi:10.1002/dmrr.2432

159. Mcentyre CJ, Lever M, Chambers ST, George PM, Slow S, Elmslie JL, et al. Variation of betaine, N,N-dimethylglycine, choline, glycerophosphorylcholine, taurine and trimethylamine-N-oxide in the plasma and urine of overweight people with type 2 diabetes over a two-year period. Ann Clin Biochem (2015) 52(Pt 3):352. doi:10.1177/0004563214545346 
160. Rabinowitch IM. Effects of betaine upon the cholesterol and bilirubin contents of blood plasma in diabetes mellitus. Can Med Assoc J (1936) 34(6):637.

161. Xu X, Gammon MD, Zeisel SH, Bradshaw PT, Wetmur JG, Teitelbaum SL, et al. High intakes of choline and betaine reduce breast cancer mortality in a population-based study. FASEB J (2009) 23(11):4022-8. doi:10.1096/ f. $09-136507$

162. Lu MS, Fang YJ, Pan ZZ, Zhong X, Zheng MC, Chen YM, et al. Choline and betaine intake and colorectal cancer risk in Chinese population: a case-control study. PLoS One (2015) 10(3):e0118661. doi:10.1371/journal. pone. 0118661

163. Zhou RF, Chen XL, Zhou ZG, Zhang YJ, Lan QY, Liao GC, et al. Higher dietary intakes of choline and betaine are associated with a lower risk of primary liver cancer: a case-control study. Sci Rep (2017) 7(1):679. doi:10.1038/s41598-017-00773-w

164. Sun S, Li X, Ren A, Du M, Du H, Shu Y, et al. Choline and betaine consumption lowers cancer risk: a meta-analysis of epidemiologic studies. Sci Rep (2016) 6:35547. doi:10.1038/srep35547

165. Lee JE, Giovannucci E, Fuchs CS, Willett WC, Zeisel SH, Cho E. Choline and betaine intake and the risk of colorectal cancer in men. Cancer Epidemiol Biomarkers Prev (2010) 19(3):884-7. doi:10.1158/1055-9965.EPI09-1295
166. Cho E, Holmes M, Hankinson SE, Willett WC. Nutrients involved in one-carbon metabolism and risk of breast cancer among premenopausal women. Cancer Epidemiol Biomarkers Prev (2007) 16(12):2787. doi:10.1158/ 1055-9965.EPI-07-0683

167. Sun J, Wen S, Zhou J, Ding S. Association between malnutrition and hyperhomocysteine in Alzheimer's disease patients and diet intervention of betaine. J Clin Lab Anal (2017) 31(5):1-7. doi:10.1002/jcla.22090

168. Detopoulou P, Panagiotakos DB, Antonopoulou S, Pitsavos C, Stefanadis C. Dietary choline and betaine intakes in relation to concentrations of inflammatory markers in healthy adults: the ATTICA study. Am J Clin Nutr (2008) 87(2):424-30. doi:10.1093/ajcn/87.2.424

Conflict of Interest Statement: The authors declare that the research was conducted in the absence of any commercial or financial relationships that could be construed as potential conflicts of interest.

Copyright (C) 2018 Zhao, He, Wu, Li, Li, Deng, Zhu, Ren and Peng. This is an open-access article distributed under the terms of the Creative Commons Attribution License (CC BY). The use, distribution or reproduction in other forums is permitted, provided the original author(s) and the copyright owner are credited and that the original publication in this journal is cited, in accordance with accepted academic practice. No use, distribution or reproduction is permitted which does not comply with these terms. 